\title{
Crowdfunding for medical expenses
}

$\mathrm{F}$ orget about fundraising with signs and spaghetti dinners. When a friend or relative needs help paying medical bills, many Americans are turning their social network into a safety net through a growing number of online fundraising platforms.

But some observers say these websites are a symptom of the failing health care system in the United States — and hardly a solution.

Websites like GiveForward, IndieGoGo, GoFundMe and YouCaring have been launched in the US over the past five years. GiveForward is the only site primarily focused on medical campaigns, and cofounder Ethan Austin says he's seen people raise US\$50 000 in a day.

"This is such a gigantic need, we didn't really anticipate how big it was," he says.

The concept is an extension of community fundraisers often held when people get sick. The websites help users connect their campaign to social media like Twitter and Facebook to solicit donations from family, friends and even strangers. It's a kind of 'crowdfunding' — where many people chip in to fund a cause or project that took off on sites like KickStarter for entrepreneurs. Most crowdfunding sites take a percentage of the money raised by each campaign, usually between $3 \%$ and $7 \%$.

Since its launch in 2008, GiveForward campaigns have raised over US\$8.8 million, and about 7600 campaigns have been completed, Austin says. Other fundraising sites accept campaigns for categories such as tuition, mission trips, start-ups or art projects. But at GoFundMe, the largest percentage of campaigns are health-related, and at YouCaring the majority of donations are in the area of medical expenses, according to their founders.

Austin says the popularity of these websites shows how desperate many Americans are when a relative or friend gets sick. "People don't want to be seen

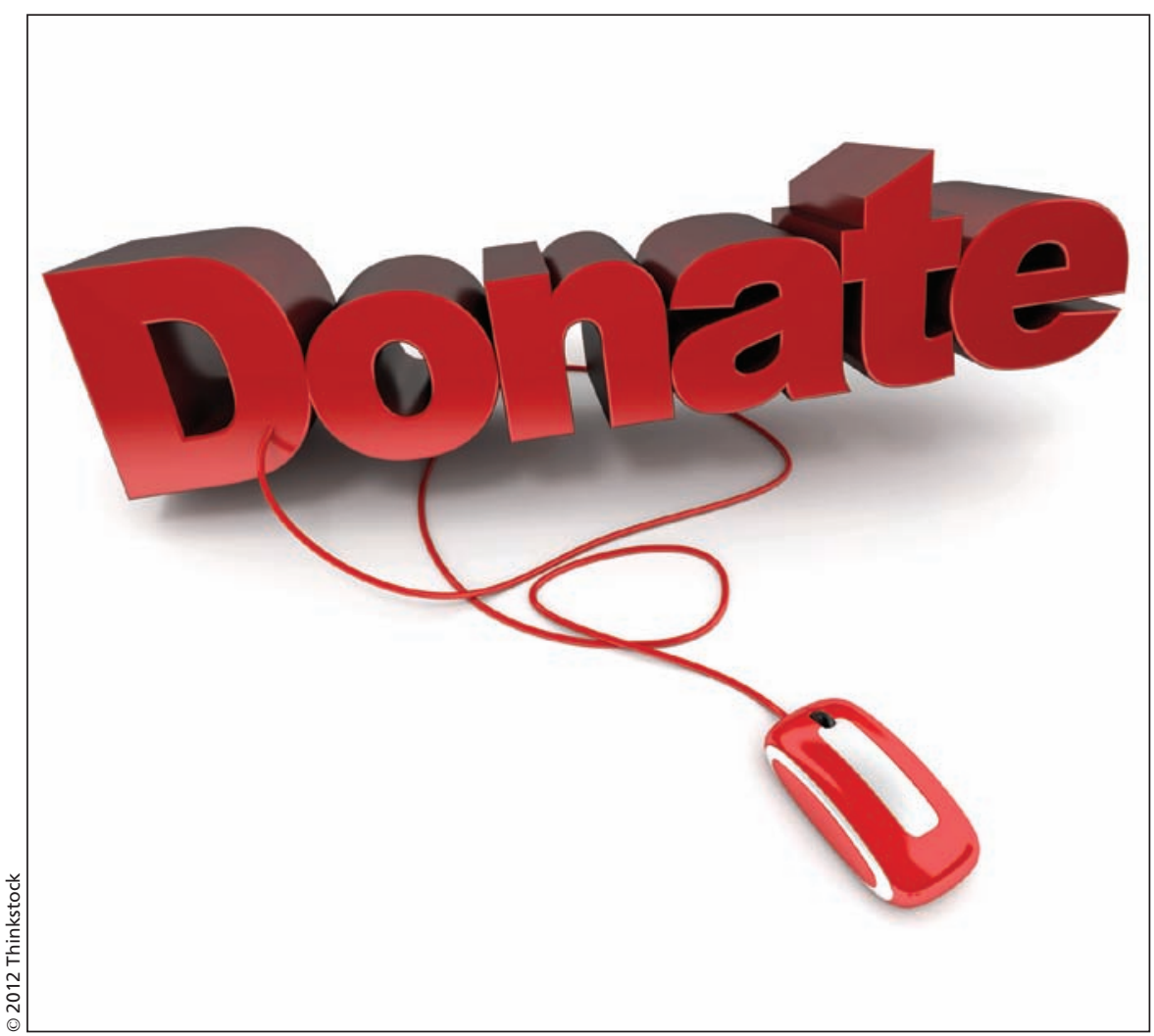

With medical expenses the leading cause of personal bankruptcies in the United States, an increasing number of desperate Americans are turning to websites to raise money to pay for medical bills of relatives and friends.

as a charity case. But we're all in the same boat, unless you're Warren Buffett or Bill Gates or someone who's mega-rich, we all could use a little extra help when someone gets sick."

Medical expenses are the leading cause of bankruptcy in the United States, according to a study that indicated about $62 \%$ of personal bankruptcies in 2007 were reportedly due to medical bills, even though most of those people had insurance - up from about 46\% in 2001 (Am J Med 2009; 122[8]:741-6).

The average amount of money raised for a GiveForward health campaign is US\$2650, though some have topped US\$80 000.

Ultimately, the growth of these websites is sad, but not surprising, given that simply tens of millions of Americans don't have insurance, says
Dr. Ida Hellander, director of health policy for the Physicians for a National Health Program, a nonprofit organization which advocates for universal health care.

"I wouldn't even say it's a band-aid — it's sort of a desperate attempt to help a few people," she says. "It shows how desperate people are, and it shows the magnitude of the crisis and the fact that the political will is not there to help people."

Many Americans are driven to fundraise on the Internet because they do not have, or have inadequate, health insurance, she says. 'It's certainly no solution, and it's probably not even a solution for the person raising the money - it just might help with this week's bill."

Many of the campaigns on GiveForward and other sites appear to be 
aimed at generating funds for an emergency, a specific treatment or recommended diagnostic tests. Rarely do they appear aimed at chronic illnesses or long-term care.

The growth of crowdfunding sites points to the need for a broader cultural change in America than is possible through the use of crowdfunding, she adds. "It reflects the unethical and immoral health care system that pushes its citizens to have to essentially beg for money on the Internet."

Others are concerned about the impact Internet fundraising will have on the US health care system.

It could slow progress toward a solution, says Rebecca Dresser, Daniel Noyes Kirby Professor and professor of ethics in medicine at the Washington University Law School in St. Louis,
Missouri. "You might say to the extent it [a fundraising website] relieves the burden, it takes pressure off society and people in government to have a more effective health care system."

Crowdfunding sites should raise questions, like any decision about giving money, Dresser contends. True friends are different than Facebook friends, she points out, and you should trust that your money will go towards a real medical condition before donating. "If you're trying to use your resources wisely, you should think about - what are alternative beneficiaries of my money? ... Do I trust this person? I would want to find out - what is your medical situation? What has the doctor recommended?"

There is always the possibility of abuse of Internet fundraising, as evidenced by the case of Ashley Kirilow of
Burlington, Ontario, who in 2010 faked having cancer and used a Facebook page to help raise thousands of dollars.

But Austin says there's only been one case of fraud at GiveForward in the past three years, and the site holds donations in an escrow account until a campaign is over, so staff have time to investigate questionable Web pages and return monies to donors if necessary. Other websites forward monies to the recipient as soon as they're raised but encourage users to identify and flag suspicious campaigns.

Dresser suggests it might be more effective to donate that money to a registered charity or a nonprofit group that has a systematic way of distributing funds. - Julia Sisler, Ottawa, Ont.

CMAJ 2012. DOI:10.1503/cmaj.109-4084 